\title{
Chemistry and Racism: A special topics course for students taking general chemistry at Barnard College in Fall 2020
}

Lauren Babb ${ }^{1}$, Rachel Narehood Austin²*

${ }^{1}$ Department of Chemistry, University of Maine, Orono ME

2 Department of Chemistry, Barnard College, 3009 Broadway, NY NY 10027

\section{ABSTRACT}

Science education research has shown that systemic racism, microaggressions, and unwelcoming or unsupportive climates disproportionally impact the ability of some individuals to flourish in chemistry. In order to help students taking general chemistry learn about the impact of systemic racism in chemistry and to provide them with a venue to discuss this issue, a special seminar-style course was created. This relatively low intensity course successfully created a space for intense conversation, reflection, increased understanding of some of the aspects of racism in chemistry, and the impetus for institutional change. A description of the course, along with student opinions, and co-facilitator reflections, are presented.

\section{GRAPHICAL ABSTRACT}

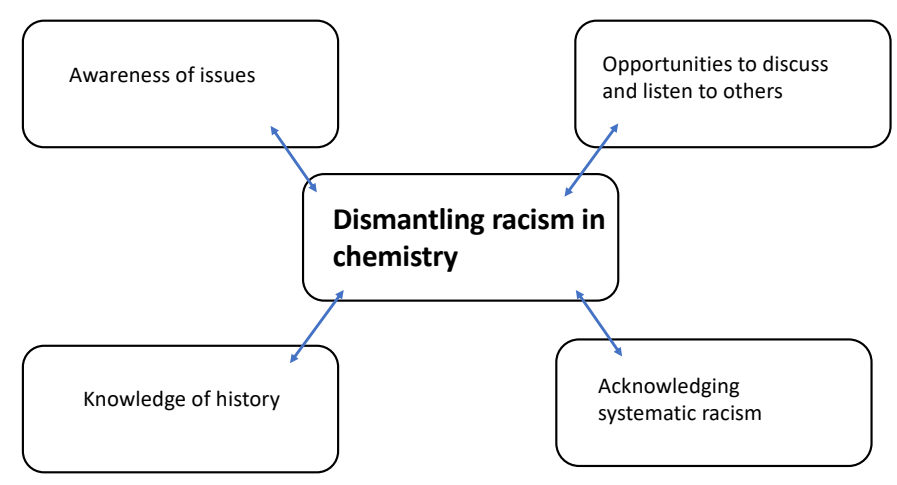

\section{KEYWORDS}

Audience: Chemistry educators, administrators, and students, Domain: racism, diversity and inclusion, 
On August 14th, Barnard College announced that the fall semester would be fully remote. Teaching remotely in the spring semester when NYC was the global epicenter of the COVID-19 pandemic was primarily a matter of getting by. Knowing that an entire semester of chemistry instruction would be fully on-line created an entirely new set of challenges. The summer of 2020 was also marked by a very high level of public awareness of the degree to which systemic racism remains pervasive in American public life, which also led to an on-going public discussion of racism in science ${ }^{1,2,3,4}$. In the late summer, seven students and recent alums sent the chemistry department a letter asking us to consider changes that would begin to dismantle racist practices within the department. In the face of the dual challenges of teaching chemistry on-line and the need to acknowledge that black lives matter, the Department of Chemistry at Barnard College decided to create a new course "BC CHEM 1004 Special Topics: Chemistry and Racism".

This course was one of five different special topics courses that the department decided to create and offer concurrently with general chemistry (BC CHEM 2001) in order to create small seminar-style experiences that linked general chemistry with topics that lent themselves to more active student engagement.

All of the special topics courses were taught by the instructor of general chemistry. She had no special expertise in anti-racist pedagogy and had not taught a course like this before. She was however a member of a special task-force charged with advising the provost on academic matters during the pandemic and in that role had reviewed a college-wide survey of student experiences in the spring. Student comments about what worked, and more importantly, what had not worked during the spring, were particularly helpful in shaping this course and the fully remote general chemistry course to which it was connected.

Our general impression of the course was that it served several important needs. It provided a small seminar-like space where students could discuss racism and chemistry. It also helped the department think about the issues raised in the student/alumni letter, which in turn has led to changes.

When we began working on the course, we did not find many other models in chemistry. The only relevant course we found is a course entitled "Being Human in Stem"5, which began at Amherst 
College but has now spread to a few other institutions. A search of this journal found no examples of courses on racism in chemistry. We hope that publication of this article will lead to the formation of a clearing house where information on courses on racism, or maybe better antiracism, in chemistry can be shared. This special issue will hopefully bring together some of the best evidence-based practices for creating inclusive, diverse, and respectful chemistry classrooms as well.

\section{Objectives of the course}

The objectives of the course were to provide students with an opportunity to discuss racism and chemistry and to offer recommendations to the chemistry department for ways to change practices and pedagogy to make the department less racist and to create environments that would be more inclusive and would enable more students to flourish.

The course provided opportunities for students to discuss topics of accessibility and inclusivity more broadly with professors and administrators collaboratively strive for equity in the classroom.

\section{Course details}

The course was a six-week, 0.5 credit, P/F course that met once a week for an hour. It was cofacilitated by a recent alum who is currently a Ph.D. candidate in chemistry. There were 12 students taking the class for credit. Of these, all but one was currently enrolled in general chemistry. Several other interested chemistry majors joined the class occasionally. Guest speakers were brought in to enrich and give perspective on discussion topics relating to institutional change.

The class began by considering the current state of affairs in science in the US and in the department. Students watched a recording of a recent town hall meeting ${ }^{6}$ June 11th, 2020) at the Zuckerman Institute at Columbia (Barnard College and Columbia University are affiliated with each other) where Professors Robert E Fulilove (Professor of Sociomedical Sciences at Columbia University Medical Center and Associate Dean Community and Minority Affairs) and Professor Olajide Williams (Professor Neurology and co-director of Columbia's Community Wellness Center) discussed the interactions between racism, history, and public health equity and justice. While their conversation was not strictly about chemistry, it did focus on science and public health and the local setting helped 
reinforce the idea that the class was going to focus on both the global and the local. Students in the class also read the letter that had been sent to the department from students and alumni. They used the first class meeting to set ground rules for discussion. Students were also given the opportunity to attend a virtual private screening of the 2020 film "Picture a Scientist"7.

Class discussions every week after the first week were led by a team of students, selected at random at the beginning of the semester. The second class focused on the issue of representation in chemistry departments in the US. Data compiled by Oxide (the Open Chemistry Collaborative in Diversity Equity ${ }^{8}$ ) formed the bulk of the material students reviewed before class. Secondary readings included a recent letter from the 2020 ACS President Luis Echegoyen on ACS commitments and actions to diversity ${ }^{9}$, inclusion, \& respect and a recent JACS essay from Professor Melanie Stanford 10 about an "actions not words" approach to equity and inclusion in the chemical sciences. Students 90 learned about career stages, academic ranks, tenure, and the process of receiving grants and the career implications associated with grant funding. This information provided important context to the demographic information provided, where students observed the obvious discrepancies. ${ }^{11,12}$

In the third week, students considered the voices and histories of black American chemists. Students read a selection from the book: Beyond Small Numbers, Volume 4: Voices of African American PhD Chemists (Diversity in Higher Education) Willie Pearson $\mathrm{Jr}^{13}$. They also read an article from CEN "Nine black chemists you should know"14 and about "Nurturing black chemists"15. Together also looked at some web pages ${ }^{16}$ of organizations created and run by black scientists and chemists to support other black scientists and chemists.

Students opened the discussion with a series of complex questions, such as, "How do we distinguish between progress and trying to fill quotas?", "How do we move the responsibility of including Black people in STEM away from Black people themselves to non-Black individuals?", "How do we take the responsibility off Black students in STEM to be the face of all Black students in STEM?", and "How do we promote Black women in academia?". Four major themes of tokenism, academia, intersectionality, and responsibility emerged in the student led discussion.

The fourth week students read a selection of articles about best practices in creating institutional change ${ }^{17,18}$. The Director of the Center for Engaged Pedagogy at Barnard College (Dr. Jennifer 
Rosales) attended one class and offered her perspective on best practices for effective pedagogical change. These readings prompted our students to reflect on how the life experiences of a professor impacts their quality of learning and even perhaps the scientific information we learn.

After getting a sense of the broader context, the last two weeks of the semester were refocused on the Barnard-specific context. Students revisited the recommendations made in the letter to the department from the summer and reaffirmed their sense for the importance of some of the recommendations and modified others.

General Chemistry (BC CHEM 2001) was redesigned to address some of the same concerns that motivated the creation of this special topics course. This special topics course on racism and chemistry also influenced the concurrent general chemistry course. In particular, General Chemistry in Fall 2020 did not have any timed closed book exams, a point that students in the racism and chemistry class pointed to as being important in helping students from a wide variety of backgrounds succeed in their first chemistry course. The decision not to have timed closed book exams was prompted by dislike for the technological options available for hosting them and knowledge that remote learning can exacerbate an already existing class differences among students ${ }^{19,} 20$ Instead, students had weekly homework assignments from a commercial chemistry homework source (Sapling), a weekly open book and class notes (but no random internet searching and no discussion with peers) take home problem written by the instructor, and a weekly check-in in which students were asked to summarize what they had learned each week, what they were still having difficulty with, and what they had learned about how to manage their own learning. The instructor read every weekly check-in and responded, which provided a way to get to know the students and their particular circumstances, despite having almost 200 students enrolled in the class. ${ }^{21}$ After feedback from students in the midsemester evaluation (survey instrument provided in supplemental material), the weekly problems were modified to highlight the work of a contemporary scientist, drawing on many examples of female or non-white scientists. ${ }^{22}$ Student assessment of the general chemistry course (provided in the supplemental material) indicated that the absence of timed exams enhanced student engagement with the class and that the weekly check-ins helped to build a sense of community and caring in the remote fall 2020 landscape. 


\section{Evaluation of the course, personal reflections:}

The course was evaluated using the standard Barnard and Columbia College course evaluation form. Students are asked to rate the course and the instruction in a variety of ways on a scale of 1 (poor) -5

(excellent). Information about the departmental and college averages for all questions are also provided to the instructor along with anonymized versions of the responses after grades are submitted. We also reflected on the class in our last session together. Students pointed to a number of aspects of the course they found important. The course began with the premise that systemic racism exists in chemistry, in the academy, and at Barnard ${ }^{23}$, a starting point that several students said was very important to them. The course scored well by Barnard College standards, receiving a 5 for the overall quality of the course. (A summary of the survey instrument and student responses is provided in the supplemental material). Interestingly, of the students who responded to the question about whether the course inspired them to put in extra time and effort beyond what was required, most said yes that they continued to read and think about the issues raised after the assigned reading was over. One of the students in the course has been working with faculty in the department in which she is majoring in (neuroscience) to try to replicate the course in some form in that department.

As a co-facilitator of this course, and recent graduate of the college I interacted with prospective majors and provided them with social insights into the field of Chemistry as I experience it as a graduate student. Intersectionality was a concept that our students eagerly embraced on the first day of classes. As this was an intimate seminar style course led by student facilitators, we challenged our students to bring their discomfort, confusion, and frustrations into the space. Each week we engaged with students' personal reflections and remarks on assigned readings that empowered us all to face uncomfortable truths and postulate anti-racist solutions we can implement as students, educators, and administrators. One student thinking contrary to social norms may be ignorable, but an entire generation of students might just change the status quo. Envision those students eventually growing to be educators and possibly administrators, challenging their peers along the way to be equitable in their classrooms, labs, and staff-meetings. How do we begin to progress in a system that has such 
small margins for opportunity and peer acknowledged excellence? One way is to make spaces that welcome students, alums, faculty, staff, and interested community members to talk about it, write about it, and recommend ways to promote equitable practices in our institution.

As the other co-facilitator of the course, and as the chair of the chemistry department, I knew we needed to offer a course that dealt with racism and chemistry. My next thought, after deciding we needed to offer a course on this topic, was that I was ill prepared to teach it. I was aware of some of the very thoughtful scholarship on antiracism and education and knew that I was not a scholar in that area. However, one of the things that impressed me as I read statement after statement from the Black Lives Matter (BLM) movement was how tired black people were of explaining over and over the basic premises of racism in America. The opening lines of the Zuckerman town hall that we had students watched reinforced the idea that we cycle through the same patterns of incident to concerns to committee formation to committee report to moderate to no action over and over. I kept reading that it was time for white people to do some of the work educating others about systemic racism. I agreed and decided to try to teach a course on racism in chemistry. Ultimately, especially in the relatively modest format that we settled on, it was not that difficult. There is a lot of information that is easily accessible and that provides useful reading material for students and the starting point for fruitful discussions. For me, focusing on our local context was grounding. Our department has been able to continue the discussions about racism in chemistry at Barnard and make changes. And we've committed ourselves to having regular discussions about racism and inclusion with our students.

\section{Future directions:}

This course has made it apparent that there need to be regular opportunities for students in chemistry to talk about racism. While it is obvious to every chemistry teacher that each year a new group of students needs to learn about atomic and molecular orbitals, sometimes there is an unexamined sense that if racism and chemistry has been discussed once, that should be enough. It is not.

We hope this course might inspire the creation of an interdisciplinary course co-taught by faculty from STEM, Ethnic Studies, and/or Women, Gender, and Sexuality Studies departments to examine 
the social, historical, and political context of racism in science. If we are to improve diversity and representation within the field, perhaps addressing topics of access and historical exclusivity early in a student's degree-seeking program might positively impact the demographic representation of future generations of scientists.

\section{ASSOCIATED CONTENT}

Supporting Information

The Supporting Information is available on the ACS Publications website at DOI:

10.1021/acs.jchemed.XXXXXXX. [

Letter from students mentioned in the article (PDF)

Survey instruments used to evaluate the course and the accompanying general chemistry course and summary of student responses. (PDF)

\section{AUTHOR INFORMATION}

Corresponding Author

*E-mail: raustin@barnard.edu

\section{ACKNOWLEDGMENTS}

We want to thank all of the students in the Chemistry and Racism course. We also want to thank Dr. Jennifer Rosales. Director of the Center for Engaged Pedagogy at Barnard College for her participation in the class and her support. Finally, we want to thank all of the members of the Chemistry Department at Barnard College, including the students and alumni who wrote the original letter around which much of the class was framed, for their eagerness to tackle the project of dismantling racism in the pockets where we have agency.

\section{REFERENCES}

1 Thorp, H. Holder. Time to look in the mirror, Science, 2020368 (6496), 1161.

2 Odekunle, Esther A. Dismantling systemic racism in science, Science, 2020, 369 (6505), 780-781.

${ }^{3}$ Menon, Binuraj R. K. The missing colours of chemistry, Nature Chemistry, 2021, 13, 101-106. 
${ }^{4}$ Burrows, Cynthia J. et al. Confronting Racism in Chemistry Journals, J. Chem. Ed., 2020, 97 (7), 1695-1697.

${ }^{5}$ http://www.beinghumaninstem.com/ (accessed Feb 2021)

${ }^{6}$ https://www.youtube.com/watch?v=hYE6rAEZ0EI\&t=1s (accessed Feb 2021).

7 https://www.pictureascientist.com/ (accessed Feb 2021)

8 http://oxide.jhu.edu/2/

9 https://www.acs.org/content/acs/en/membership-andnetworks/acs/welcoming/diversity/diversity-inclusion-and-respect-letter-august-2020.html

10 Sanford, Melanie E. Equity and Inclusion in the Chemical Sciences Requires Actions not Just Words, J. Am. Chem. Soc. 2020, 142 (26), 11317-11318.

11 https://cen.acs.org/articles/93/i20/New-Survey-Minority-Chemistry-Professors.html (accessed March 2021)

12 https://diversity.nih.gov/building-evidence/racial-disparities-nih-funding (accessed March 2021)

13 Pearson, William Jr. Beyond Small Numbers, Volume 4: Voices of African American PhD Chemists (Diversity in Higher Education) pp 1-87 (need to check this because since we read chapter 9 I think the pages that show up are from the excepting - can get Barnard Science librarian to help us with this.

${ }^{14}$ https://cen.acs.org/people/profiles/Six-black-chemists-should-know/97/web/2019/02 (accessed Feb 2021)

15 https://cen.acs.org/education/Nurturing-Blackchemists/98/i34?utm_source=Newsletter\&utm_medium $=$ Newsletter\&utm_campaign $=C E N$ (accessed Feb 2021)

16 https://www.stemnoire.org/ (accessed Feb 2021)

17 https://hbr.org/2020/06/restructure-your-organization-to-actually-advance-racialjustice?cid=email\%7Celoqua\%7Cthe $\% 20$ faculty\%20lounge $\% 207-21-20$-a $\% 7$ C562431\%7Cfacultylounge-newsletter\%7Cnewsletter-subscribers\%7Cvarious\%7Cjul20201948\&acctID=13016136 (accessed Feb 2021)

18 Canning, Elizabeth A.; Muenks, Katherine; Green Dorainne J.; Murphy, Mary C. STEM faculty who believe ability is fixed have larger racial achievement gaps and inspire less student motivation in their classes, Sci. Adv., 2019, 5:eaau4734

19 https://www.edweek.org/technology/the-disparities-in-remote-learning-under-coronavirus-incharts/2020/04 (accessed March 2021)

20 https://www.epi.org/publication/the-consequences-of-the-covid-19-pandemic-for-educationperformance-and-equity-in-the-united-states-what-can-we-learn-from-pre-pandemic-research-toinform-relief-recovery-and-rebuilding/ (accessed March 2021) 
${ }^{21}$ Dewsbury, Bryan.; Brame, Cynthia J. Inclusive Teaching, CBE-Life Sciences Education, 2019, 18(2) fe2 1-5.

22 Goff, Peter; Boesdorfer, Sarah B.; Hunter, William. Using a multicultural approach to teach chemistry and the nature of science to undergraduate non-majors. Cult. Stud. Of Sci. Educ. 2012, 7, 631-651.

${ }^{23}$ Hodson, Derek. Going Beyond Cultural Pluralism: Science Education for Sociopolitical Action. Sci. $E d, 1999,83,775-796$. 